\title{
Analysis and Material Balances of Pig Iron Plant using Energy Audit
}

\author{
Sachin R. Kale ${ }^{+*}$, Abhijit A. Kadam ${ }^{\dagger}$, Sudhanwa Kulkarni ${ }^{\dagger}$ and Vipul Ruiwale ${ }^{\dagger}$ \\ †Pune University, MIT College of Engineering, \\ Accepted 02 March 2016, Available online 15 March 2016, Special Issue-4 (March 2016)
}

\begin{abstract}
An energy audit is a study of a plant or facility to determine how and where energy is used and to identify methods for energy savings. There is now a universal recognition of the fact that new technologies and much greater use of some that already exist provide the most hopeful prospects for the future. The opportunities lie in the use of existing renewable energy technologies, greater efforts at energy efficiency and the dissemination of these technologies and options. Energy Audit attempts to balance the total energy inputs with its use and serves to identify all the energy streams in the systems and quantifies energy usages according to its discrete function. Energy Audit helps in energy cost optimization, pollution control, safety aspects and suggests the methods to improve the operating and maintenance practices of the system. This energy audit of the SESA Goa Ltd is carried out by the Department of Energy Science and renewable energy group for saving the wastage of energy. This report is just one step, a mere mile marker towards our destination of achieving energy efficiency and we would like to emphasis that an energy audit is a continuous process. We have compiled a list of possible actions to conserve and efficiently utilize our scarce resources and identified their savings potential. The next step would be to prioritize their implementation. We look forward with optimism that the institute authorities, staff and students shall ensure the maximum execution of the recommendations and the success of this work.
\end{abstract}

Keywords: GEPL, GCS, BFG, OHSAS.

\section{Introduction}

The Pig Iron Plant at Amona has two Mini blast furnaces with working volume of 173 M3 each. The first Blast furnace was commissioned in March 1992 and the second in July 1994. The basic function of a blast furnace is to remove the oxygen from the iron oxide (ore) and bring the temperature of the reduced iron to well above its melting point. This process is carried out by the counter current reaction between descending raw materials from top \& ascending reducing gases from bottom The raw materials namely iron ore and fluxes (limestone and dolomite) along with coke (reducing agent \& fuel) are charged into the blast furnace from top. The hot air is introduced through the openings called tuyeres located above hearth \& this heated air burns coke charged from the furnace top to produce the heat required by the process and also generates reducing gases that preheat raw material and remove oxygen from the ore descending through the stack. The molten metal and slag thus collected in hearth are tapped time to time. The liquid metal is collected in a refractory lined ladle and cast into small blocks called pigs in Pig Casting Machines. The different grades of pig iron are

*Corresponding author: Sachin R. Kale produced depending upon customers' requirements. The slag, a by-product generated during smelting of iron ore, is granulated \& sold to cement manufacturers.

The company has been certified for Quality System ISO 9001(2000), Environment System ISO14001 (2004) and Occupational health and Safety system OHSAS 18001:1999 The company has its own Captive Power plant of 3 MW Capacity run on steam produced from waste heat boiler using blast Furnace Gas. The total blast furnace gas (BFG) available from two blast furnaces, after self consumption (used for air preheating) can produce around $8 \mathrm{MW}$ of power with heat rate of $3300 \mathrm{Kcal} / \mathrm{kWh}$. Existing $3 \mathrm{Mw}$ power plants which was installed in 1991 is of inefficient design by current standards and takes around 4700 $\mathrm{Kcal} / \mathrm{kwh}$. As energy conservation measure Company 18 decided to scrap the existing power plant and go for efficient design higher capacity plant which can also make use of additional BFG available. Accordingly a 30 Mw power plant has been installed by a third party who is using BFG as fuel along with coke oven waste heat produced from coke oven plant of Sesa the parent company.

The Company also receives Grid supply from Govt. of Goa at 33KV. During non availability of grid supply and power plant, DG sets are operated. However from June 2007, power from GEPL plant is made available to 
Sesa as such grid and DG power is not required is used only during emergency. However due to the inability of GEPL to utilize full quantity of BFG available with us, due to technical constraints like under sizing of pipe line and fan, considerable quantity of BFG was being flared to atmosphere. To save on valuable resources, Company decided to run its $3 \mathrm{MW}$ Power Plant and accordingly it was run till July- 12 .

\section{Methodology}

To maintain a clear focus on the objective of improving overall energy utilization, the team typically performs an energy audit in ten sequential tasks. This approach is taken to insure adequate dialog between energy auditors \& client at key junctures during the exercise so that only energy conservation measures (ECMs) that are feasible from an operation and maintenance perspective are evaluated in-depth and incorporated into the final recommendations

Step 1 - Interview with Key Facility Personnel: During the initial audit, a meeting was scheduled between the auditor and all key operating personnel to start the project. The meeting agenda focuses on: audit objectives and scope of work, facility rules and regulations, roles and responsibilities of project team members, and description of scheduled project activities. In addition to thee administrative issues, the discussion during this meeting seeks to establish: operating characteristics of the facility, energy system specifications, operating and maintenance procedures, preliminary areas of investigation, unusual operating constraints, anticipated future plant expansions and other concerns related to facility operations.

Step 2 - Facility Tour: After the initial meeting, a tour of the facility is arranged to observe the various operations first hand, focusing on the major energy consuming systems identified during the interview, including the architectural, lighting and power, mechanical, and process energy systems.

Step 3 - Document Review: During the initial visit and subsequent meetings, available facility documentation are reviewed with facility representatives. This documentation includes all available architectural and engineering plans, facility operation and maintenance procedures and logs, and utility bills for the previous years.

Step 4 - Facility Inspection: After a thorough review of the construction and operating documentation, the major energy consuming processes in the facility are further investigated. Where appropriate, field measurements are collected to substantiate operating parameters.

Step 5 - Staff Interviews: Subsequent to the facility inspection, the audit team meets again with the facility staff to review preliminary findings and the recommendations being considered. Given that the objective of the audit is to identify projects that have high value to the customer, management input at this juncture helps establish the priorities that form the foundation of the energy audit.

Step 6 - Utility Analysis: The utility analysis is a detailed review of energy bills from the previous 12 to 36 months. If possible, energy data is obtained and reviewed prior to visiting the facility to insure that the site visit focuses on the most critical areas. Billing data reviewed includes energy usage, energy demand and utility rate structure. The utility data is normalized for changes in climate and facility operation and used as a baseline to compute projected energy savings for evaluated ECM's.

Step 7 - Identify/Evaluate Feasible ECMs: Typically, an energy audit will uncover both major facility modifications requiring detailed economic analysis and minor operation modifications offering simple and/or quick paybacks. A list of major ECMs is developed for each of the major energy consuming systems. Based upon a final review of all information and data gathered about the facility, and based on the reactions obtained from the facility personnel at the conclusion of the field survey review, a finalized list of ECMs is developed and reviewed with the facility manager

Step 8 - Economic Analysis: Data collected during the audit is processed and analyzed back in offices. We build models and simulations with software to reproduce field observations and develop a baseline against which to measure the energy savings potential of ECMs identified.

\section{Step 9 - Prepare a Report Summarizing Audit}

Findings: The results of the findings and recommendations are summarized in a final report. The report includes a description of the facilities and their operation, a discussion of all major energy consuming systems, a description of all recommended ECMs with their specific energy impact, implementation costs, benefits and payback. The report incorporates a summary of all the activities and effort performed throughout the project with specific conclusions and recommendations.

Step 10 - Review Recommendations with Facility Management: A formal presentation of the final recommendations is presented to facility management to supply them with sufficient data on benefits and costs to make a decision on which ECMs to be implemented. 


\section{Process of Manufacturing}

The raw materials for making pig iron are

3. Iron Ore (Ferrous Oxide)

4. Coke (carbon)

5. Lime stone

6. Dolomite

7. Hot Air

The iron ore is fed in to the Blast furnace along with coke. The blast furnace basically does the function of converting iron oxide in to liquid iron. Coke is used as a reducing agent as well as fuel. The output from the furnace is the pure iron in molten stage and slag, which is called hot metal.

Pig iron- definition- Liquid iron from blast furnace solidified in moving metal moulds of a "Pig Casting Machine".

Products (outlet stream)

- Pig iron

- Slags

- BF gas

Partial combustion of coke takes places in the furnace producing carbon monoxide reducing ferrous oxide of the ore to pig iron. In the process of making pig iron slag and gases (called BF gas) are generated. Molten iron \& slag are withdrawn from the bottom of furnaces, while BF gas is let out from the top.

$\mathrm{BF}$ gas is mainly mixture of carbon dioxide \&carbon monoxide. This gas has a heating value. The BF gas coming out of furnace contains particulate matter and hence this gas is cleaned. The part BF gas is supplied for power generation to another company [GEPL] and rest of the gas is burnt in stoves as a heat recovery system.

The stoves are recuperative - regenerative heat recovery system. The stove works as heat storage. There are three numbers of stoves. The BF gas is burnt in stove for certain time, heating the stove and storing he heat. In next cycle, burning of BF gas is stopped and fresh air (required for combustion of coke in BF) is circulated thus heating the air. The heated air is supplied for combustion of coke in BF.

Out of three numbers of stoves, two stoves are always under firing mode and the third stove is heating the air. The technical parameters of temperature, pressure and flow rates are mentioned in the report. Water is spread over the outer surface of the furnace to maintain stipulated temperature inside the furnace. This water is cooled in cooling tower. Thus two water pumps supply to furnace (cooling tower pump) and return water pump from furnace to cooling tower are in operation round the clock. For BF gas cleaning system, one pump for each furnace in operation round the clock. In addition slag granulation pump is operated as and when required.

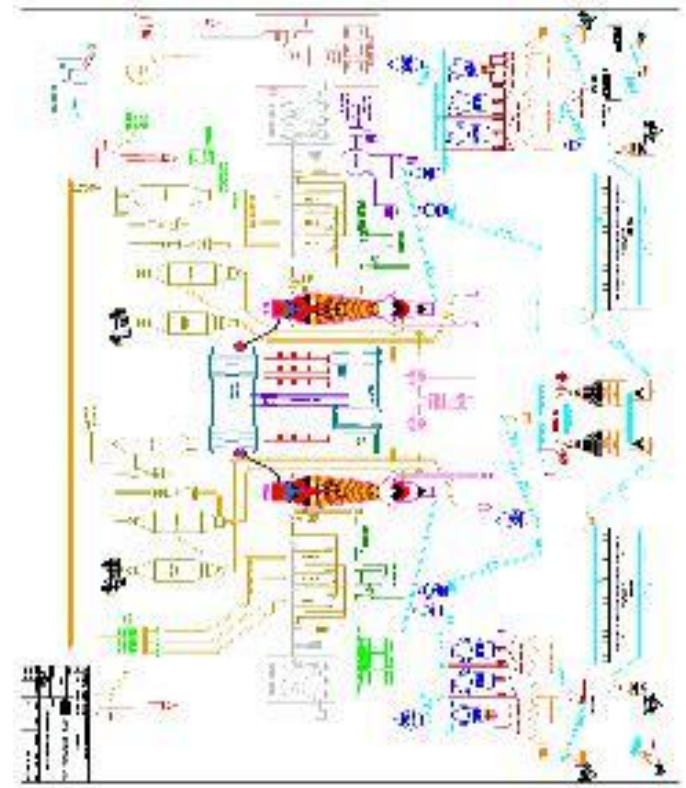

Figure 1: Flow sheet of manufacturing process

\section{Observations \& Measurements}

As stated earlier, raw material for pig iron making are iron ore , coke \& air. The material \& energy balance of the blast furnace \& stove was studied with a view to explore the possibility raw material saving. Electrical consumption of major energy cost centers is covered in the later part of the report. The detailed material \& energy balance of the blast furnace $\&$ stove is written below.

Material balance across blast furnace

Table No: 1 - Input Material

\begin{tabular}{|c|c|}
\hline Material & Quantity \\
\hline Iron ore & $23,750 \mathrm{~kg} / \mathrm{h}$ \\
\hline Coke & $9,500 \mathrm{~kg} / \mathrm{h}$ \\
\hline Air & $25,530 \mathrm{~N} \mathrm{cum} / \mathrm{h}=32,927 \mathrm{~kg} / \mathrm{h}$ \\
\hline Total & $66,177 \mathrm{~kg} / \mathrm{h}$ \\
\hline
\end{tabular}

Table No: 2 - Output Material

\begin{tabular}{|c|c|}
\hline Material & Quantity \\
\hline Iron melted & $15,000 \mathrm{~kg} / \mathrm{h}$ \\
\hline Slag & $4,000 \mathrm{~kg} / \mathrm{h}$ \\
\hline BF gas & $\begin{array}{c}36,000 \mathrm{~N} \mathrm{cum} / \mathrm{h}=48,960 \mathrm{~kg} / \mathrm{h} \\
\text { (Den }: 1.36 \mathrm{~kg} / \mathrm{cum} \text { ) }\end{array}$ \\
\hline Total & $67,960 \mathrm{~kg} / \mathrm{h}$ \\
\hline
\end{tabular}

Chemical reactions involved in making of pig iron

Basis: 3 mole of $\mathrm{Fe}_{2} \mathrm{O}_{3}$

- $3 \mathrm{Fe}_{2} \mathrm{O}_{3}+\mathrm{CO}=2 \mathrm{Fe}_{3} \mathrm{O}_{4}+\mathrm{CO}_{2}$ 
- $2 \mathrm{Fe}_{3} \mathrm{O}_{4}+\mathrm{CO}=6 \mathrm{FeO}+\mathrm{CO}_{2}$

- $6 \mathrm{FeO}+6 \mathrm{CO}=6 \mathrm{Fe}+6 \mathrm{CO}_{2}$

Thus 3 moles of $\mathrm{Fe}_{2} \mathrm{O}_{3}$ generates 6 moles of $\mathrm{CO}_{2} .479 .1$ $\mathrm{kg}$ of $\mathrm{Fe}_{2} \mathrm{O}_{3}$ generates $352 \mathrm{~kg}$ of $\mathrm{CO}^{2}$

\section{Material Balance:}

- Iron ore quantity : $23,750 \mathrm{~kg} / \mathrm{h}$

- Fe203 content in iron ore : $19,287.3 \mathrm{~kg} / \mathrm{h}(82 \%)$

- $\quad 479.1 \mathrm{~kg}$ of $\mathrm{Fe} 2 \mathrm{O} 3$ generates $352 \mathrm{~kg}$ of $\mathrm{CO}_{2}$.

Hence $19,287.3 \mathrm{~kg} \mathrm{Fe}_{2} \mathrm{O}_{3}$ generates $14,170 \mathrm{~kg} / \mathrm{h}$ of $\mathrm{CO}_{2}$

BF gas contains $29.72 \% \mathrm{CO}_{2}$ by weight,

- Weight of BF gas : 48,960 kg/h

- Weight of CO2 in BF gas : 14,552.73 kg/h

[Close to worked out stoichiometrically]

The above analysis indicated that $\mathrm{CO}_{2}$ coming in $\mathrm{BF}$ gas is generated by reduction of ferrous oxide only. The $\mathrm{CO}_{2}$ is not generated by combustion of carbon. Hence the potential for reducing or optimizing the air for blast furnace are nil.

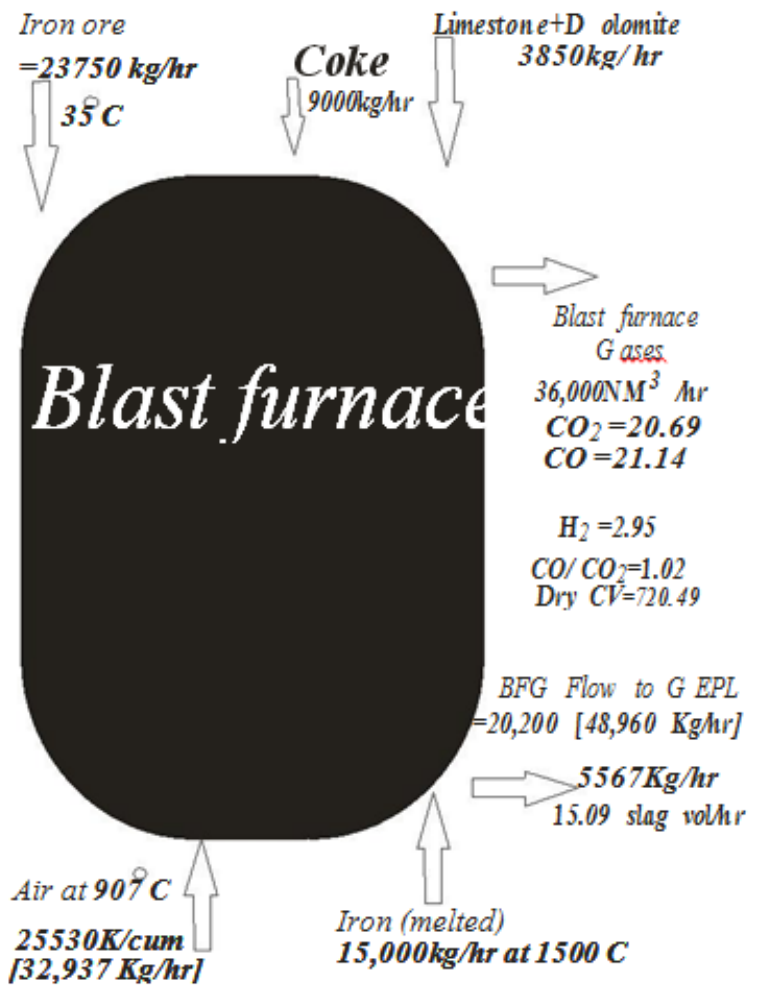

Figure 2: Material balance of blast furnace

\section{Electricity Consumptions}

In Material balance of blast furnace

\begin{tabular}{|c|c|c|}
\hline Major energy cost Centre & KW & \% load \\
\hline Blowers of Blast Furnace (1 \& 2) & 3000 & 67 \\
\hline CT Water Pump BF1 \& BF 2 & 300 & 6.7 \\
\hline Return Water Pump BF1 \& BF 2 & 150 & 3.3 \\
\hline Gas Cleaning Pumps BF1 \& BF 2 & 150 & 3.3 \\
\hline Air Compressor & 150 & 3.3 \\
\hline Bag House BF 1 & 150 & 3.3 \\
\hline Bag House BF 1 & 200 & 4.5 \\
\hline air blowers at stove & 78 & 1.7 \\
\hline Lighting ( reported ) & 300 & 6.7 \\
\hline Total & $\mathbf{4 4 7 8}$ & $\mathbf{1 0 0}$ \\
\hline
\end{tabular}

The above electrical consumption was measured and it indicates that above electrical loads, which operates round the clock (barring lighting) contributes more than $95 \%$ of electrical load.

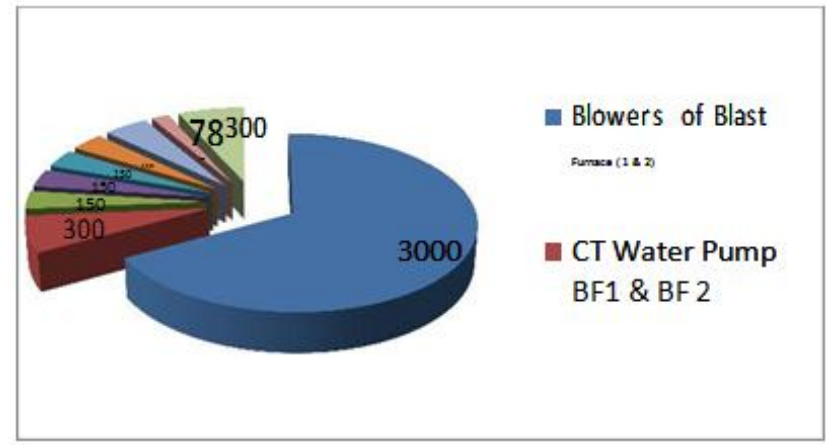

Figure 3: Electricity Consumptions

\section{Results and Discussions}

Sesa Goa constantly endeavors to optimize the consumption of materials in all its operations and processes. The major materials used in the process of mining operations are:

- Lubricants used for HEMM operation.

- Steel for structural fabrication.

- Paint

- Explosive for breaking hard strata.

Steel and paint are used in the ship-building unit and the support services of the mining division. At Sesa Industries, the major raw materials used are iron ore, met coke and fluxes. Iron ore is supplied partly from the mining division; the balance is purchased from the open market. Coke is supplied by the met coke division of the Company. Fluxes are purchased from outside. The Company makes continuous efforts to bring down specific coke consumption. During the reporting period, raw material, fluxes and coke consumption decreased due to installation and effective use of hot blast stoves, due to reduction in the quantity of pig iron production. The graphs below show consumption patterns of raw materials at the pig iron plant during the last three years. The major raw material in cokemaking is low ash coal, which is imported. Our Company does not have any process which can reuse 
industrial waste as raw materials. Sesa Goa constantly endeavors to optimize the consumption of materials in all its operations and processes. The major materials used in the process of mining operations are: Steel and paint are used in the ship-building unit and the support services of the mining division. At Sesa Industries, the major raw materials used are iron ore, met coke and fluxes. Iron ore is supplied partly from the mining division; the balance is purchased from the open market. Coke is supplied by the met coke division of the Company. Fluxes are purchased from outside. The Company makes continuous efforts to bring down specific coke consumption. During the reporting period, raw material, fluxes and coke consumption decreased due to installation and effective use of hot blast stoves, due to reduction in the quantity of pig iron production. The graphs below show consumption patterns of raw materials at the pig iron plant during the last three years. The major raw material in cokemaking is low ash coal, which is imported. Our Company does not have any process which can reuse industrial waste as raw materials.

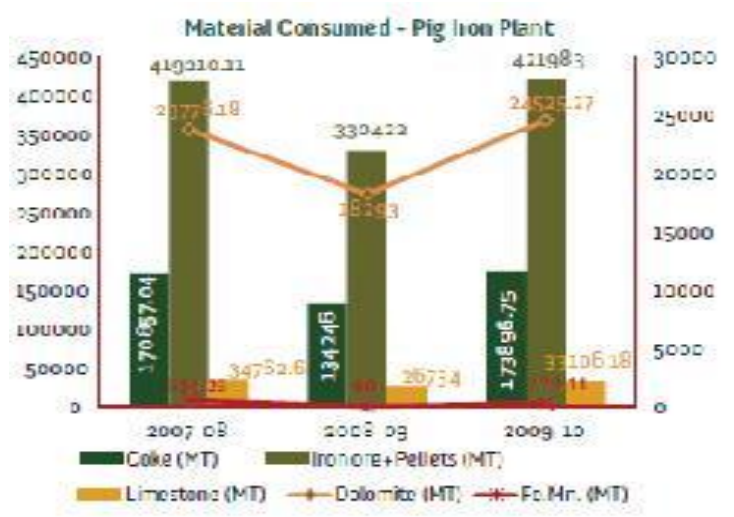

Figure 4: Material consumption

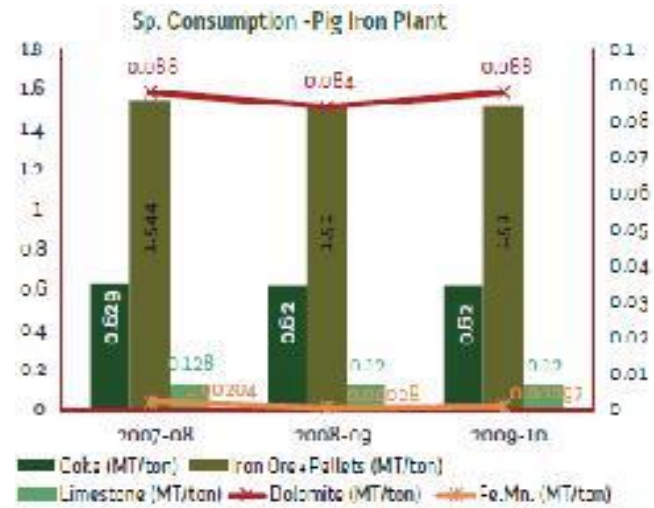

Figure 5: Specific material consumption

\section{References}

T. Markis, J.A. Paravantis (2007), Energy conservation in small enterprises, Energy and Buildings, 404-415.

Pantelis N. Botsarisa, Spyridon Prebezanos (2004), A methodology for a thermal energy building audit, Building and Environment, 195 - 199.

M. Siddhartha Bhatt (2000),, Energy audit case studies -I (steam systems), Applied Thermal Engineering, 285-296.

M. Siddhartha Bhatt (2000), Energy audit case studies -II (Air conditioning cooling system), Applied Thermal Engineering, 297-307.

Ali Alajmi (2012), Energy audit of an educational building in a hot summer climate, Energy and Buildings, pp122-130.

Sofia Klugman, Magnus Karlsson, Bahram Moshfegh, Scandinavian (2007), Chemical wood-pulp mill Energy audit aiming at efficiency measures, Applied Energy, 326-339.

Jojo S.M. Li (2008), A study of energy performance and efficiency improvement procedures of Government Offices in Hong Kong Special Administrative Region, Energy and Buildings, 18721875.

Shi-Ming Deng (2000), John Burnett, A study of energy performance of hotel buildings in Hong Kong, Energy and Buildings. 7-12.

Liu Xuezhia (2011), Cui Ying, Analysis of Enterprise Energy Audit Countermeasure in China, Energy Procedia, 1893-1897. 